\title{
Hypoxia upregulates expression of human endosialin gene via hypoxia-inducible factor 2
}

\author{
A Ohradanova', K Gradin', M Barathova', M Zatovicova', T Holotnakova', J Kopacek', S Parkkila ${ }^{3}$, \\ L Poellinger ${ }^{2,4}$, S Pastorekova ${ }^{1,4}$ and J Pastorek ${ }^{*, 1,4}$ \\ 'Centre of Molecular Medicine, Institute of Virology, Slovak Academy of Sciences, Dubravska cesta 9, Bratislava 845 05, Slovak Republic; ${ }^{2}$ Department of \\ Cell and Molecular Biology, Karolinska Institutet, Stockholm 17177, Sweden; ${ }^{3}$ Institute of Medical Technology and School of Medicine, University of \\ Tampere, Biokatu 6, FIN-330I4, Finland
}

Endosialin is a transmembrane glycoprotein selectively expressed in blood vessels and stromal fibroblasts of various human tumours. It has been functionally implicated in angiogenesis, but the factors that control its expression have remained unclear. As insufficient delivery of oxygen is a driving force of angiogenesis in growing tumours, we investigated whether hypoxia regulates endosialin expression. Here, we demonstrate that endosialin gene transcription is induced by hypoxia predominantly through a mechanism involving hypoxia-inducible factor-2 (HIF-2) cooperating with the Ets-I transcription factor. We show that HIF-2 activates the endosialin promoter both directly, through binding to a hypoxia-response element adjacent to an Ets-binding site in the distal part of the upstream regulatory region, and indirectly, through Ets-I and its two cognate elements in the proximal promoter. Our data also suggest that the SPI transcription factor mediates responsiveness of the endosialin promoter to high cell density. These findings elucidate important aspects of endosialin gene regulation and provide a rational frame for future investigations towards better understanding of its biological significance.

British Journal of Cancer (2008) 99, I 348- 1356. doi: I 0. I038/sj.bjc.6604685 www.bjcancer.com

Published online 23 September 2008

(C) 2008 Cancer Research UK

Keywords: endosialin; HIF-2; Ets-I; hypoxia; angiogenesis

Endosialin (alternatively named TEM1 or CD248) is a highly glycosylated single-pass transmembrane protein proposed to become a marker of tumour vasculature and a target for anticancer therapy (Teicher, 2007). Endosialin was discovered with a monoclonal antibody (MAb) raised against human foetal fibroblasts as an antigen selectively expressed in tumour blood vessels and absent in normal human tissues (Rettig et al, 1992). Independently, TEM1 (tumour endothelial marker 1) was linked to tumour endothelium by serial analysis of gene expression (St Croix et al, 2000). Identity of endosialin with TEM1 was then demonstrated by Christian et al (2001), who cloned its full-length cDNA, and based on the domain composition and homology to thrombomodulin classified endosialin as a C-type lectin-like receptor.

Subsequent studies have confirmed that endosialin is upregulated in blood vessels and activated stromal fibroblasts in human colorectal, brain and breast tumours as well as in mouse xenograft models (Carson-Walter et al, 2001; Brady et al, 2004; Davies et al, 2004; Madden et al, 2004; Dolznig et al, 2005; MacFadyen et al, 2005, 2007; Huber et al, 2006; Rupp et al, 2006). Endosialin expression is restricted to capillaries and shows a heterogeneous pattern typical for molecules involved in vascular reorganisation.

*Correspondence: Professor J Pastorek; E-mail: virupast@savba.sk

${ }^{4}$ These authors are senior authors.

Received 10 April 2008; revised 29 August 2008; accepted 29 August 2008; published online 23 September 2008
Moreover, abundant endosialin expression was found in the vasculature and fibroblast-like cells of the developing mouse and human embryos (Rupp et al, 2006; MacFadyen et al, 2007; Virgintino et al, 2007). Using a gene targeting approach, Nanda et al (2006) have shown that endosialin is dispensable for normal development and subcutaneous tumour growth, but can modulate invasiveness and metastatic progression in an orthotopic xenograft model of colorectal cancer. All these data support the functional involvement of endosialin in angiogenesis, a complex process of vascular branching and sprouting that plays a key role in tumour expansion and progression, and therefore represents an opportunity for therapeutic intervention against cancer.

Recent antiangiogenic strategies are based on targeting the molecules selectively expressed in tumour vessels (Fukumura and Jain, 2007). From this viewpoint, expression pattern and possible functional implication in angiogenesis make endosialin a promising subject of clinical investigations. However, present research suffers from inadequate knowledge of factors and pathways that control endosialin expression and determine its tissue distribution. There is only a single study showing that mouse endosialin gene transcription is induced by high cell density, but the underlying molecular mechanism has not been elucidated (Opavsky et al, 2001).

Angiogenesis is well known to be principally driven by hypoxia in growing solid tumours as well as in developing embryos (Liao and Johnson, 2007). Hypoxia often develops in intratumoral areas with deficient or functionally inadequate blood vessels. Insufficient delivery of oxygen then promotes multiple adaptive responses 
including angiogenesis, which facilitates new blood supply and allows for further tumour expansion (Harris, 2002). This adaptation process is governed by hypoxia-inducible transcription factors, notably HIF-1 and HIF-2. In normoxia, the $\alpha$-subunits of HIFs are modified by oxygen-dependent prolyl hydroxylases (PHDs), interact with the von Hippel-Lindau tumour-suppressor protein, and undergo rapid ubiquitination and proteasomemediated degradation. Hypoxia leads to inactivation of PHDs, stabilisation of the $\alpha$-subunits, their translocation into the nucleus, heterodimerisation with the constitutive $\beta$-subunit, and formation of an active transcription complex (Ruas and Poellinger, 2005). Hypoxia-inducible factors can transactivate a large spectrum of genes contributing to adaptation, including proangiogenic factors VEGF (vascular endothelial growth factor), ANG2 (angiopoietin 2) and their receptors (Hickey and Simon, 2006; Ruas et al, 2007).

Here, we provide the first evidence that hypoxia induces expression of endosialin predominantly through the HIF-2 transcription factor. We have identified cis-elements in the upstream regulatory region of the human endosialin gene that mediate the hypoxic responses and demonstrate that these elements bind HIF-2 in both direct and indirect manners. Moreover, we show that upregulation of endosialin by high cell density is mediated by the SP1 transcription factor and is partly caused by pericellular hypoxia. Thus, these combined transcriptional regulatory mechanisms are important for intratumoral expression of endosialin.

\section{MATERIALS AND METHODS}

\section{Cell culture}

All cell lines, including human HeLa cervical carcinoma cells, 42MG-BA glioblastoma cells (Perzelová et al, 1998), FIB-3 placental fibroblasts, mouse NIH3T3 fibroblasts, b.END3 brain endothelial cells and the HIF-1 $\beta$-deficient Hepa-1c4 hepatoma cells (Legraverend et al, 1982) were cultured in DMEM with 10\% FCS (BioWhittaker, Verviers, Belgium) in a humidified atmosphere with $5 \% \mathrm{CO}_{2}$ at $37^{\circ} \mathrm{C}$. The cells were exposed to hypoxia $\left(2 \% \mathrm{O}_{2}\right)$ in an anaerobic workstation (Ruskinn Technology, Bridgend, UK) in 5\% $\mathrm{CO}_{2}, 2 \% \mathrm{H}_{2}$ and $91 \% \mathrm{~N}_{2}$ at $37^{\circ} \mathrm{C}$. Hypoxia was also induced chemically with $100 \mu \mathrm{M}$ 2,2'-dipyridyl (DIP, Sigma, St Louis, MO, USA).

\section{Reporter promoter constructs}

The endosialin-luc promoter construct was generated by an insertion of a $-1091 /+43$ endosialin genomic region amplified by PCR upstream of the firefly luciferase gene in pGL3-basic luciferase reporter vector (Promega, Madison, WI, USA). Deletion and mutant variants of the promoter were generated from this construct by PCR using the primers mentioned in the Supplementary information. Deletion variant $-285 /+43$ was created by SacI digestion.

\section{Expression plasmids}

Human HIF- $1 \alpha$ and mouse HIF- $2 \alpha$ cDNAs in pcDNA1/Neo plasmid were kindly provided by Professor Patrick Maxwell, Imperial College of Science, Technology and Medicine, London, UK. Expression plasmid pCMV-HIF- $1 \beta$ containing human HIF- $1 \beta$ / ARNT cDNA was described previously (Whitelaw et al, 1993). Expression plasmids CMV-Sp1 containing human SP1 cDNA and SP(RSV)AP-2 containing human TFAP2A/AP-2 cDNA were purchased from Addgene (Cambridge, MA, USA). pcDNA3.1/ Neo/Ets-1 expression plasmid was created by insertion of $1571 \mathrm{bp}$ human Ets-1 cDNA fragment amplified by RT-PCR into pcDNA3.1 $(+)$ (Invitrogen, Carlsbad, CA, USA). Human endosialin cDNA was amplified using endosialin_F1 and endosialin_R1 primers and cloned into phCMV1 expression vector (Genlantis, San Diego, CA, USA). For prokaryotic expression, the endosialin cDNA fragment encoding the amino acids 192-675 was amplified and cloned into pGEX-4T-1 plasmid (Amersham Biosciences, Chalfont St Giles, UK).

\section{Generation of endosialin-specific MAb}

$\mathrm{BALB} / \mathrm{c}$ mice were immunised with two doses of $5 \times 10^{6} \mathrm{HeLa}$ cells transfected with endosialin cDNA in a phCMV1 expression vector and boosted with $100 \mu \mathrm{g}$ GST-endosialin protein bound to Glutathione Sepharose 4B. Fusion of spleen cells with Sp2/0 myeloma cells was carried out 3 days later. Monoclonal antibodies produced by the hybridomas were screened for the specific reactivity towards endosialin protein in HeLa-endosialin vs HeLamock cells by ELISA and immunoblotting. The hybridoma culture (M78) was subcloned by limiting dilution, expanded and used for the MAb production.

\section{RNA isolation and reverse transcription PCR}

Total RNA was extracted from cells using the NucleoSpin RNA II kit (Macherey-Nagel, Düren, Germany) and reverse transcribed with the M-MuLV reverse transcriptase (Finnzymes, Espoo, Finland) using random heptanucleotides as primers. Polymerase chain reactions were performed using the primers for endosialin (endosialin_F2, R2), VEGF-A, $\beta$-actin and DyNAmo HS SYBR Green qPCR Kit (Finnzymes). Following an initial denaturation at $95^{\circ} \mathrm{C}$ for $10 \mathrm{~min}$, the amplification programme was set to denaturation at $95^{\circ} \mathrm{C}$ for $30 \mathrm{~s}$, annealing at $60^{\circ} \mathrm{C}$ for $40 \mathrm{~s}$ and extension at $72^{\circ} \mathrm{C}$ during $40 \mathrm{~s}$ for a total of 40 cycles, and finally $5 \mathrm{~min}$ at $72^{\circ} \mathrm{C}$.

\section{Transient transfection and luciferase assay}

The cells were plated into $35 \mathrm{~mm}$ Petri dishes to reach approximately $70 \%$ monolayer density on the next day. Transfection was performed with $2 \mu \mathrm{g}$ of pGL3-based promoter construct and $100 \mathrm{ng}$ of $\mathrm{pRL}-\mathrm{TK}$ plasmid DNAs using a GenePorterII reagent (Genlantis). Alternatively, $1 \mu \mathrm{g}$ of pGL3-based promoter construct, $1 \mu \mathrm{g}$ of expression vector containing the transcription factor's cDNA and $50 \mathrm{ng}$ of pRL-TK plasmids were transfected. One day later, the transfected cells were trypsinised and plated in triplicates into 24-well plates. The cells were allowed to attach overnight and then transferred to hypoxia for additional $24 \mathrm{~h}$. Reporter gene expression was assessed using the Dual-Luciferase Reporter Assay System (Promega) and the luciferase activity was normalised against the renilla activity.

\section{Immunoblotting}

FIB-3 and 42-MG-BA cells were plated in sparse (12000 cells $\mathrm{cm}^{-2}$ ) or dense $\left(48000\right.$ cells $\left.\mathrm{cm}^{-2}\right)$ cultures, left to attach overnight and then incubated for $24 \mathrm{~h}$ in normoxia and hypoxia, respectively. Proteins were extracted with cold RIPA buffer (1\% Triton X-100, $0.1 \%$ sodium deoxycholate and $1 \mathrm{x}$ Complete protease inhibitor cocktail (Roche, Mannheim, Germany) in PBS) for $15 \mathrm{~min}$ at $4^{\circ} \mathrm{C}$, and total protein concentrations were determined by BCA assay (Pierce, Rockford, IL, USA). Samples of 50-80 $\mu$ g were separated by SDS-PAGE and blotted onto the PVDF membrane. The membrane was treated with M78 MAb in undiluted hybridoma medium followed by the peroxidase-conjugated goat anti-mouse immunoglobulins (DAKO, Glostrup, Denmark) and developed using enhanced chemiluminescence. For loading control, the membrane was probed with anti- $\alpha$-tubulin antibody (rat monoclonal YL1/2, Novus Biologicals, Littleton, CO, USA) and the polyclonal goat anti-rat IgG-HRP (Santa Cruz Biotechnology, Santa Cruz, CA, USA). 


\section{RNA interference}

RNA duplexes targeting HIF-1 $\alpha$ (Hs_HIF1A_5 HP Validated siRNA), HIF-2 $\alpha$ (Hs_EPAS1_5 HP Validated siRNA) and negative control siRNA were purchased from Qiagen (Qiagen AB, Solna, Sweden). 42-MG-BA cells were transfected with $10 \mathrm{~nm}$ siRNA using HiPerFect reagent (Qiagen) according to the manufacturer's instructions. After $24 \mathrm{~h}$ transfection, the medium was changed and cells were transferred to hypoxia for additional $24 \mathrm{~h}$. Then, proteins were extracted with cold high-salt buffer $(50 \mathrm{~mm}$ Tris- $\mathrm{HCl}$ $\mathrm{pH} 7.4,500 \mathrm{~mm} \mathrm{NaCl}, 1 \% \mathrm{NP}-40$ and $20 \%$ glycerol) supplemented with $0.5 \mathrm{~mm}$ PMSF and $5 \mathrm{~mm}$ 2-mercaptoethanol for $30 \mathrm{~min}$ at $4{ }^{\circ} \mathrm{C}$. Lysates were cleared by centrifugation for $30 \mathrm{~min}$ at $16000 \mathrm{~g}$ and subjected to immunoblotting analysis as described above.

\section{Chromatin immunoprecipitation assay}

FIB-3 cells were plated into $500 \mathrm{~cm}^{2}$ plates at the density of 12000 cells $\mathrm{cm}^{-2}$, left to attach overnight and incubated in absence or presence of $100 \mu \mathrm{m}$ DIP for $4 \mathrm{~h}$ and $24 \mathrm{~h}$. The cells were fixed in $1 \%$ formaldehyde in PBS for $10 \mathrm{~min}$ at room temperature. Chromatin isolation, shearing to a size of $\sim 600-800 \mathrm{bp}$ and its immunoprecipitation with antibodies against HIF- $1 \alpha$ (rabbit polyclonal, Santa Cruz Biotechnology), HIF-1 $\beta$ (rabbit polyclonal, Mason et al, 1994) and HIF- $2 \alpha$ (rabbit polyclonal, Novus Biologicals), was performed as described in Löfstedt et al, 2004. As a negative control and for chromatin preclearing, anti-human IgG antibodies (rabbit polyclonal, Abcam, Cambridge, UK) were used. Purified DNA was subjected to 36 cycles of PCR with primers flanking the putative hypoxia-responsive elements (HREs) (-1072HRE, -976HRE, $-574 \mathrm{HRE})$ and Ets-binding sites $(-171 /-133-\mathrm{EBS})$ within the endosialin promoter. Primers flanking the HRE of the VEGF promoter were used as a positive control.

\section{Bioinformatics}

In silico analysis of the endosialin promoter was performed using rVISTA 2.0 (Loots and Ovcharenko, 2004) and MatInspector (Quandt et al, 1995) programs.

\section{RESULTS}

\section{Hypoxia induces expression of endosialin}

In initial experiments we examined the effect of hypoxia on expression of endosialin in two human cell lines, namely FIB-3 placental fibroblasts and 42-MG-BA glioblastoma cells. The cells were exposed to hypoxia $\left(2 \% \mathrm{O}_{2}\right)$ for $24 \mathrm{~h}$, and parallel samples were incubated for the same time period in normoxia. In both cell lines, the endosialin gene showed increased expression in hypoxic conditions as demonstrated by qRT-PCR (Figure 1A). We then verified the hypoxic induction of endosialin at the protein level using our specific MAb M78 generated against $\mathrm{HeLa}$ cells transfected with the endosialin cDNA. The M78 MAb could recognise a $\sim 95 \mathrm{kDa}$ core protein as well as a $165 \mathrm{kDa}$ glycosylated form of endosialin (Figure 1B) and detected higher endosialin level (especially that of the core protein) in cells exposed to hypoxia than in normoxic cells (Figure 1C). These initial experiments represented a proof-of-concept and prompted us to analyse the transcriptional regulation of endosialin.

\section{HIF-2 transcription factor mediates hypoxic induction of endosialin}

Computer analysis of a $2 \mathrm{~kb}$ fragment of the $5^{\prime}$ flanking region of the human endosialin gene revealed several putative HRE with the core sequence $5^{\prime}$-RCGTG- $3^{\prime}$, both in sense and antisense orientations. Out of these, three HREs at positions -1072/-1065, -976/

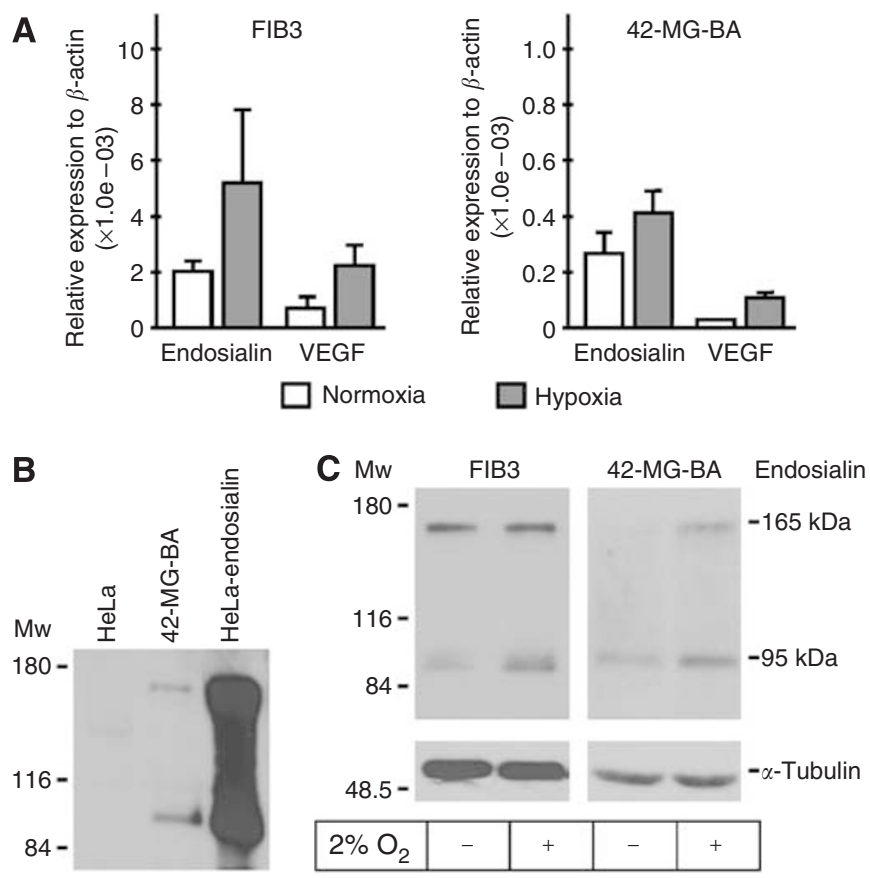

Figure I Expression of endosialin in response to hypoxia. (A) FIB-3 and 42-MG-BA cells were incubated for $24 \mathrm{~h}$ in normoxic or hypoxic conditions. Total RNA was extracted and expression of endosialin mRNA was analysed by quantitative RT-PCR and normalized to $\beta$-actin levels Vascular endothelial growth factor (VEGF) mRNA was used as a positive control. (B) Specificity of the monoclonal antibody (MAb) M78 for endosialin protein was evaluated by immunoblotting using 42-MG-BA cells that naturally express endosialin and HeLa cells transfected with endosialin cDNA (HeLa-endosialin). Mock-transfected HeLa cells served as a negative control. M78 MAb could recognise both the non-glycosylated core protein $(95 \mathrm{kDa})$ and the highly glycosylated endosialin (I65 kDa). (C) Immunoblotting analysis of endosialin protein levels in FIB-3 (50 $\mu$ g total proteins/ lane) and 42-MG-BA cells ( $80 \mu \mathrm{g}$ total proteins/lane loaded due to lower endosialin expression level, see part a). The cells were incubated for $24 \mathrm{~h}$ in hypoxia (2\% oxygen, + ) or normoxia $(-)$. M78 MAb revealed increased expression of endosialin in the hypoxic cells. $\alpha$-Tubulin antibody was used for a loading control.

-969 and $-574 /-567$ (numbered with respect to the transcription initiation site) were predicted as the conserved binding sites for the transcription factors of the HIF family.

Therefore, we cloned the $-1091 /+43$ region of the human endosialin gene into the promoter-less pGL3-basic vector and analysed its activity in a dual luciferase reporter assay. Initial attempts to perform the promoter analyses in endosialin-positive human cell lines were hampered by low survival of these cells following transfection. For this reason, we decided to use the endosialin-negative HeLa cells that are easy to transfect and have been frequently used in studies of HIF-mediated signalling. To prove that these cells enable proper transcriptional responses of the endosialin promoter, we included for comparison two mouse cell lines, namely NIH3T3 fibroblasts and b.END3 endothelial cells that naturally express the endosialin gene. In all cases, hypoxic treatment of the transfected cells led to an increased expression of the firefly luciferase gene driven by the endosialin upstream regulatory region when compared to the normoxic controls (Figure 2A). The level of hypoxic response in HeLa cells was similar to that observed in NIH3T3 and b.END3 cells. Thus, the subsequent promoter experiments were mostly carried out using this human cell line.

To test whether HIF family members are responsible for the hypoxic activation of endosialin gene, we first analysed the activity of the endosialin promoter in Hepa-1c4 cells deficient in HIF- $1 \beta$ 
(ARNT), a common heterodimerisation partner for HIF- $1 \alpha$ and HIF- $2 \alpha$. As expected, hypoxic induction of the endosialin promoter was abrogated in the absence of functional HIF-1 $\beta$, but was restored when the $-1091 /+43$ promoter construct was co-transfected with HIF-1 $\beta$ expression vector (data not shown). We then analysed the response of the endosialin promoter to HIF-1 and HIF-2 transcription factors. HeLa cells were co-transfected with the $-1091 /+43$ promoter construct together with HIF- $1 \alpha$ and HIF- $2 \alpha$ expression vectors, respectively, or with an empty expression vector, and cultivated in normoxia or hypoxia for $24 \mathrm{~h}$. Cotransfection with HIF- $1 \alpha$ resulted in modest effects on endosialin promoter activity. In contrast, expression of HIF- $2 \alpha$ led to robust, dose-dependent activation of the endosialin promoter both in normoxia and in hypoxia demonstrating that HIF- $2 \alpha$ has strong functional activity on the endosialin promoter (Figure $2 \mathrm{~B}$ and $\mathrm{C}$ ).

These findings were further supported by RNA interferencemediated knock-down of endogenous HIF- $1 \alpha$ and HIF- $2 \alpha$, respectively. Hypoxic 42-MG-BA glioblastoma cells transfected with the specific siRNAs clearly showed reduced endosialin protein level when compared to the cells transfected with the control siRNA (Figure 2D). Moreover, the effect of HIF-2 $\alpha$ knock-down was more dramatic than that of HIF- $1 \alpha$, in line with the proposed predominant role of HIF- $2 \alpha$ in endosialin regulation under hypoxia.

\section{HIF-2 regulates the endosialin promoter by binding to HRE -976/-969}

To identify regulatory elements that are responsible for the hypoxia-dependent activation, we constructed a series of $5^{\prime}$-deletion variants of the originally cloned endosialin promoter region as well as a variant with a double-point mutation in the putative HREs $-1072 /-1065$ and $-976 /-969$ (designated as mutHRE). Luciferase activity driven by these promoter variants was tested in HeLa cells incubated for $24 \mathrm{~h}$ in hypoxia and normoxia, respectively. As shown in Figure 3, maximal hypoxic induction was detected with the promoter constructs containing an intact $-1091 /-919$ region, indicating that HRE $-1072 /-1065$ and/or HRE -976/-969 might participate in the HIF-mediated response.

We next performed chromatin immunoprecipitation assays, allowing for the analysis of transcription factors binding to their cognate sequences in an innate context of the promoter. We used FIB-3 cells, which naturally express the endosialin gene as well as both the HIF- $1 \alpha$ and HIF- $2 \alpha$ subunits (data not shown). The cells were treated for 4 and $24 \mathrm{~h}$, respectively, with $100 \mu \mathrm{m}$ DIP (a cellpermeable iron chelator commonly used in the studies of hypoxic responses due to inhibition of prolyl and asparaginyl hydroxylases) to induce stable and transcriptionally active HIF proteins. After treatment, the cells were fixed with formaldehyde, their chromatin was isolated, sheared and immunoprecipitated with antibodies directed to all three subunits of HIF-1 and HIF-2 transcription factors. Precipitated DNA fragments were purified and used in PCRs together with primers flanking the putative HRE $-1072 /-1065$ and HRE -976/-969 sites, as well as the HRE - 574/ -567 site. Primers flanking the HRE $-982 /-975$ in the VEGF promoter were used for a positive control. We found that only the endosialin HRE -976/-969 showed a consistent signal for HIF-1 $\alpha$, HIF- $2 \alpha$ and HIF-1 $\beta$ in DIP-treated cells when compared to
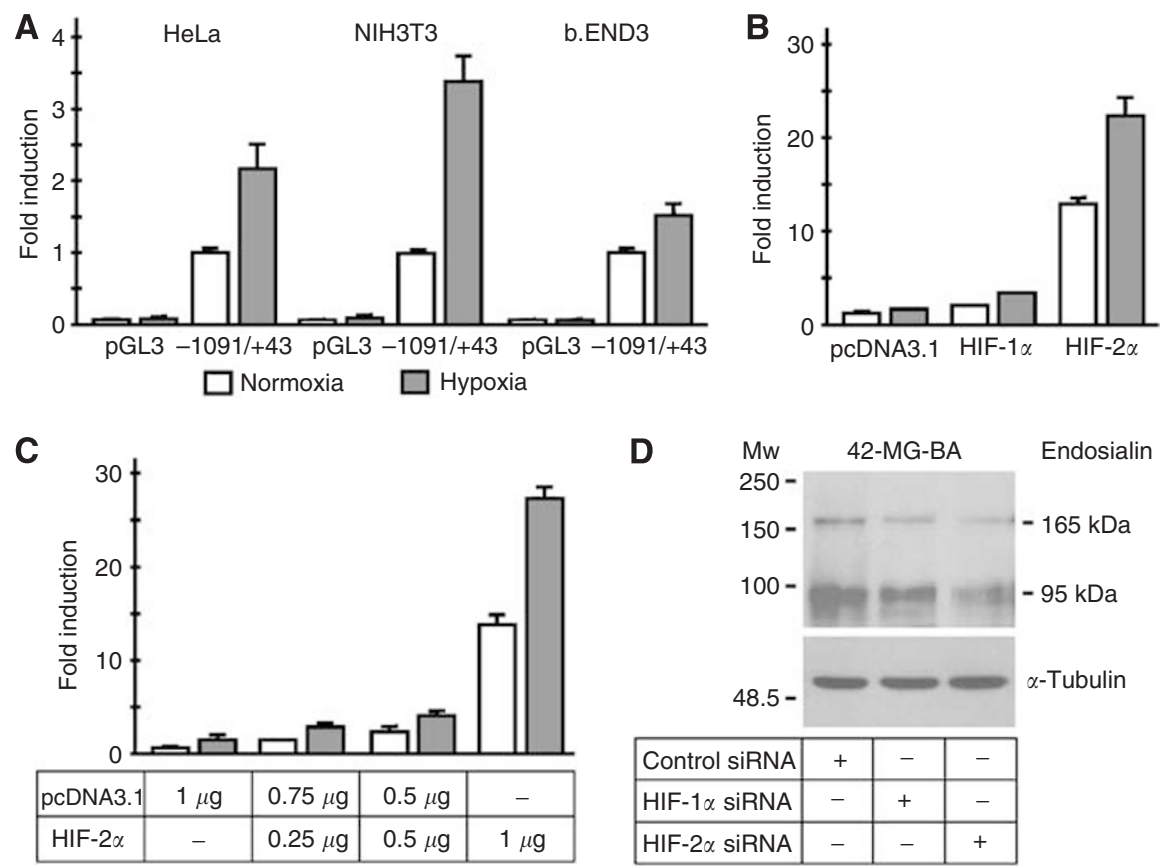

Figure 2 Effects of hypoxia, hypoxia-inducible factor (HIF)- $\mid \alpha$ and HIF-2 $\alpha$ on the activity of endosialin promoter. (A) HeLa, NIH 3 T3 and b.END3 cells were transfected with the - $1091 /$ + 43 promoter fragment in pGL3-basic luciferase vector $(2 \mu \mathrm{g})$ and pRL-TK plasmid (I00 ng). The transfected cells were incubated for $24 \mathrm{~h}$ in normoxia or hypoxia. Luciferase activity was normalised against renilla activity. Hypoxic values were expressed as a fold induction of the normoxic ones. Empty pGL3-basic plasmid was used for control of basal luciferase activity. Similar hypoxic induction was observed in all three cell lines. (B) HeLa cells were co-transfected with the $-109 \mid /+43$ pGL3-basic promoter construct ( $\mu \mathrm{g}$ ), pRL-TK plasmid (50 ng), and HIF- $\mid \alpha$ or HIF-2 $\alpha$ expression vectors ( I $\mu \mathrm{g}$ each). Empty pcDNA3.I was used to adjust total DNA content in the control sample. The transfected cells were treated in normoxia and hypoxia and the promoter activity was assessed as described above. HIF- $2 \alpha$ but not HIF- I $\alpha$ dramatically induced endosialin promoter activity. (C) HeLa cells were co-transfected with constant amounts of the - $109 \mid /+43$ pGL3-basic promoter construct ( $\mu \mathrm{g})$ and pRL-TK plasmid (50 ng), and an increasing amount of HIF- $2 \alpha$ expression vector. Total DNA was adjusted with empty pcDNA3. I. Endosialin promoter activities were assessed as above and showed a dose-dependent induction by HIF- $2 \alpha$. The induction was more prominent in hypoxia apparently due to both stabilisation and activation of HIF- $2 \alpha$ protein. (D) Immunoblotting analysis of endosialin protein level in the 42-MG-BA cells transfected with the specific HIF-I $\alpha, H I F-2 \alpha$ and control siRNAs and incubated under hypoxia for $24 \mathrm{~h}$. Both forms of endosialin were decreased after treatment with HIF- $\mid \alpha$ and HIF- $2 \alpha$ siRNAs, respectively, but the effect of HIF- $2 \alpha$ siRNA was more evident suggesting a predominant role of HIF-2 in control of endosialin expression. 
untreated control cells (Figure 4). In a manner similar to the co-transfection experiments, the signals resulting from immunoprecipitation with the anti-HIF- $2 \alpha$ antibody were stronger than those with the anti-HIF-1 $\alpha$ antibody, suggesting that HIF-2 may be a dominant factor in regulation of the endosialin promoter.

\section{HIF-2 cooperates with Ets-1}

Recently it was reported that a small group of genes, regulated by HIF-2 rather than HIF-1, have at least one HRE in proximity to an ETS transcription factor-binding site (EBS) and that HIF- $2 \alpha$ and ETS-family member physically interact and cooperate in regulation of these genes (Aprelikova et al, 2006). Consistent with this
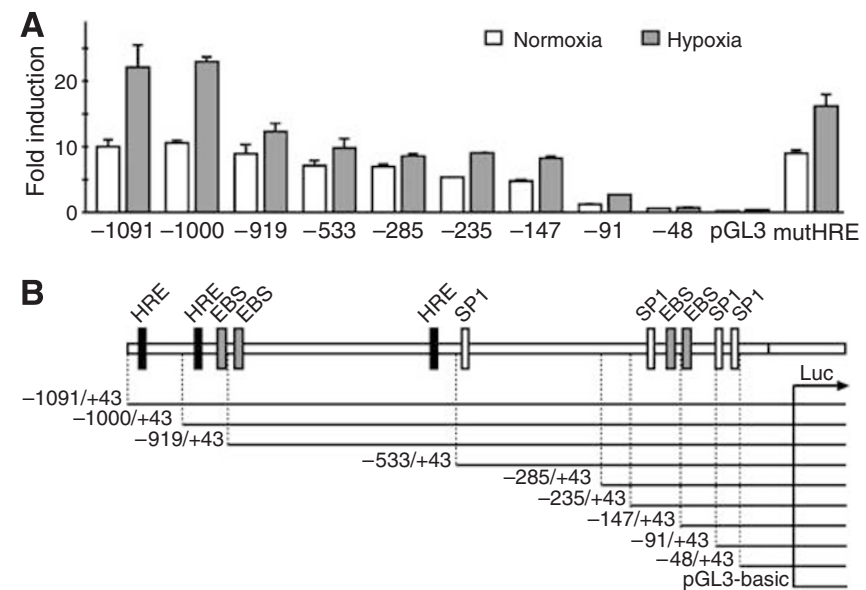

Figure 3 Localisation of hypoxia-responsive regions in the endosialin promoter. (A) HeLa cells were transfected with 5'-progressively truncated endosialin promoter fragments in pGL3-basic luciferase vector $(2 \mu \mathrm{g})$ and pRL-TK plasmid ( $100 \mathrm{ng}$ ). MutHRE construct contained mutations in two HREs (-1072/-1065 and -976/-969). The transfected cells were incubated for $24 \mathrm{~h}$ in normoxia or hypoxia. Luciferase activity was normalised against renilla activity. Empty pGL3-basic plasmid was used for control of the basal luciferase activity. (B) Scheme of the upstream regulatory region of the endosialin gene with indicated positions of predicted binding sites for transcription factors of the HIF family (HRE), ETS family (EBS) and SPI. Truncated promoter fragments are illustrated below with the $5^{\prime}$ termini scaled to scheme to facilitate allocation of the relevant cis elements. concept, two putative EBS elements were found in the endosialin promoter less than $80 \mathrm{bp}$ downstream of HRE $-976 /-969$ at positions $-935 /-919$ and $-907 /-891$. Moreover, co-transfection of the $-1091 /+43$ endosialin promoter construct with an expression vector encoding a representative member of ETS family, Ets-1, resulted in augmented endosialin promoter activity indicating that Ets-1, in fact, contributes to regulation of endosialin gene expression (Figure 5A).

To assess possible cooperation between Ets-1 and HIF-2 in regulation of endosialin gene expression, we co-transfected $\mathrm{HeLa}$ cells with the $-1091 /+43$ promoter construct and Ets- 1 and HIF- $2 \alpha$ expression vectors either separately or together. Noteworthy, the combined activating effect of Ets- 1 and HIF- $2 \alpha$ was about 2.5 times higher than that calculated for an additive effect of these two transcription factors expressed individually. This fact suggests that Ets- 1 and HIF- $2 \alpha$ act synergistically to transactivate endosialin transcription (Figure 5A). Furthermore, the $-919 /+43$ promoter fragment lacking EBS -935/-919 displayed reduced activation of the endosialin promoter by Ets-1 in the presence of HIF- $2 \alpha$ (Figure 5A), whereas no further reduction was observed when EBS $-907 /-891$ was deleted (not shown). These data strongly suggest that hypoxic induction of endosialin gene is governed by HIF- 2 transcription factor cooperating with Ets- 1 by adjacent HRE -976/-969 and EBS -935/-919 elements.

Nonetheless, the existence of the functional HRE nearly $1 \mathrm{~kb}$ upstream of the transcription start site could not explain our observation that shorter promoter constructs lacking the classical HRE sequence still remained partly hypoxia-responsive (Figure 3 ). Moreover, in the absence of any apparent HRE, these constructs responded to co-transfection with the HIF- $2 \alpha$ expression vector by increased reporter gene activity (Figure 5B). Interestingly, a similar situation was described for the core promoter of VE-cadherin gene that was transactivated by HIF- $2 \alpha$ cooperating with Ets- 1 by two EBS elements (Le Bras et al, 2007). Indeed, the endosialin promoter was found to contain two additional EBS motifs: the first one designated as Ets-1 or ELF-2-binding site (EBS -171/-156), the other one as GABP-binding site (EBS -149/-133). To investigate whether any of these putative sites is functional, we deleted either EBS -171/-156 alone or both EBS elements from the $-235 /+43$ fragment and co-transfected HeLa cells with the resulting promoter constructs in the absence or presence of Ets-1 and HIF- $2 \alpha$ vectors. As shown in Figure 5B, induction of -235 / +43 reporter gene activity caused by simultaneous as well as individual expression of Ets- 1 and HIF- $2 \alpha$ was considerably decreased following the deletion of EBS $-171 /-156$ and was almost completely abolished when both EBS elements were eliminated.

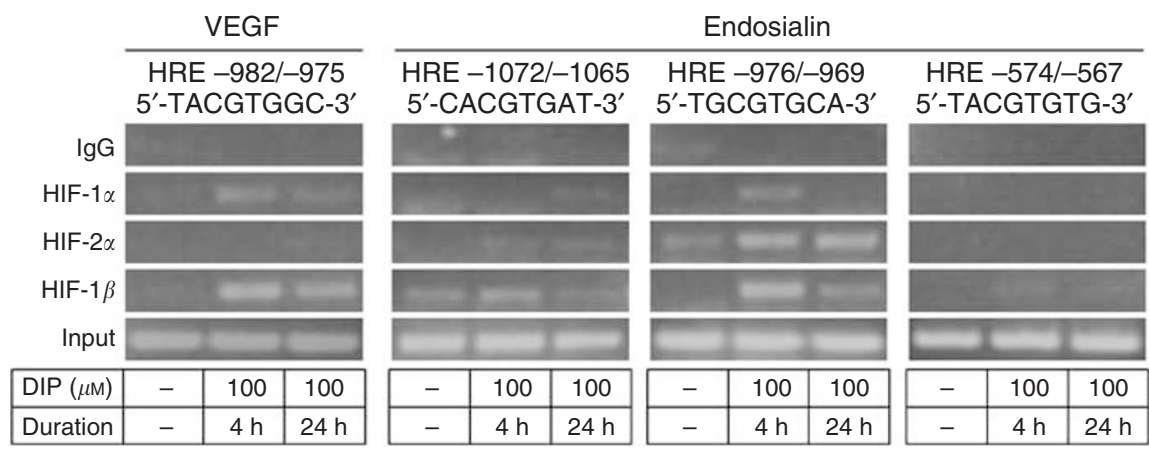

Figure 4 The binding of hypoxia-inducible factor (HIF) subunits to hypoxia-responsive elements in the endosialin promoter. Chromatin immunoprecipitation assays using FIB-3 cells treated with $100 \mu \mathrm{M}$ DIP for 4 and $24 \mathrm{~h}$, respectively. Untreated cells were used as a negative control. The cells were incubated with formaldehyde for crosslinking, DNA was extracted and immunoprecipitated with antibodies specific for HIF subunits or for human IgG antibodies to visualise background signal. Recovered DNA was used in PCR with primers flanking respective HREs. DNA samples from non-immunoprecipitated extracts were amplified as input. HIF- $2 \alpha$ was found to bind to HRE $-976 /-969$, but not to the other HREs. 

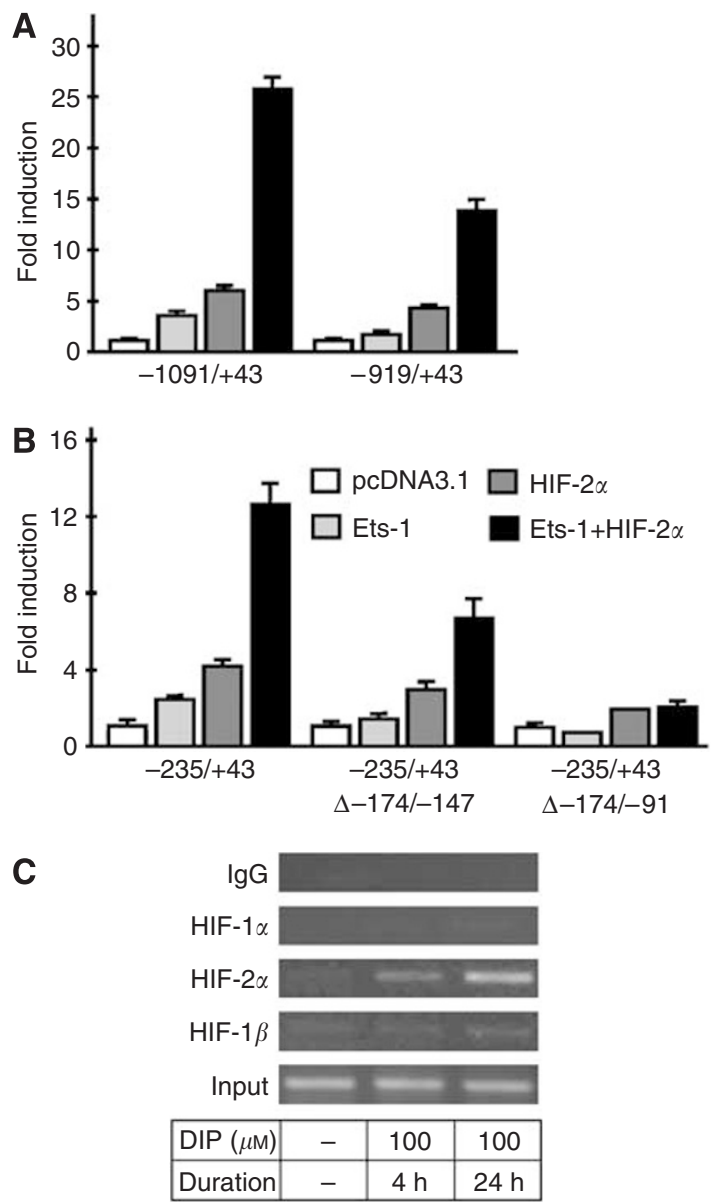

Figure 5 Cooperation between the hypoxia-inducible factor (HIF)-2 and Ets-I transcription factor. (A) HeLa cells were co-transfected with the - |09|/ + 43 or -919/ + 43 pGL3-basic promoter construct (I $\mu \mathrm{g})$, pRLTK plasmid (50 ng) and HIF-2 $\alpha$ and/or Ets-I expression vectors (I $\mu \mathrm{g}$ each). Empty pcDNA3.I was used to adjust total DNA content in all samples to $3 \mu \mathrm{g}$. The transfected cells were incubated in hypoxia and the promoter activity was assessed as described in Figure 2. Simultaneous expression of HIF-2 $\alpha$ and Ets-I showed synergic effect on endosialin promoter activity. (B) HeLa cells were transfected with the $-235 /+43$ pGL3-basic promoter construct and its mutated variants with deletions of one $(\Delta-\mid 74 /-147)$ or both $(\Delta-|74 /-9|)$ EBS elements, respectively, and pRL-TK, HIF- $\alpha$ and/or Ets-I plasmids were co-transfected as above. The graph shows the promoter activity obtained in hypoxic cells only, as a similar profile was observed in the normoxic counterparts. (C) Chromatin immunoprecipitation assay was performed on FIB-3 cells under same conditions as described in Figure 4, except that primers flanking the ETS transcription factor-binding site (EBS) elements were used to detect binding of the HIF subunits. HIF- $2 \alpha$ clearly bound to the EBS-containing region.

Moreover, we detected the physical presence of the HIF-2 transcription factor on the $-235 /-16$ endosialin promoter region by chromatin immunoprecipitation assays (Figure $5 \mathrm{C}$ ). On the basis of these results, we propose that hypoxic induction of the endosialin promoter fragment lacking apparent HREs is mediated by HIF-2 that acts in cooperation with the Ets-1 transcription factor binding to both EBS elements.

\section{SP1 activates endosialin promoter in dense cells}

Given that high cell density increases the expression of the mouse endosialin gene (Opavsky et al, 2001), we analysed the effect of cell crowding on expression levels of the human endosialin gene by
qRT-PCR. As shown in Figure 6A, increased cell density led to elevated expression of endosialin mRNA. Interestingly, endosialin expression was reduced in cells subjected to gentle stirring throughout the experiment to ensure proper oxygenation of the cell monolayer and elimination of pericellular hypoxia, which occurs in high density cultures (Sheta et al, 2001). This finding indicates that the effect of cell density on endosialin expression is partially mediated by pericellular hypoxia. To obtain further insight into a potential mechanism of transcriptional control of the human endosialin gene by cell density, we analysed the endosialin promoter activity in HeLa cells grown in sparse vs dense monolayers. We found that the $-1091 /+43$ and $-235 /+43$ promoter fragments showed more than two-fold higher activity in dense cells when compared to the sparse culture (Figure 6B). Conversely, the activity of the $-48 /+43$ promoter construct was not modulated by cell density, suggesting that the densityresponsive regulatory region is localised upstream of the nucleotide -48 .

Computer analysis of the sequence between nucleotides -235 and -48 relative to the transcriptional start site revealed that this region is GC-rich and possesses several SP1- and AP-2-binding sites. Co-transfection of the $-235 /+43$ promoter construct with either SP1 or AP-2 expression vectors clearly demonstrated that SP1 (and not AP-2) plays a role in activation of the endosialin promoter (Figure 6C). This conclusion was supported by immunoblotting analysis, which showed that density-induced induction of endosialin protein expression in 42-MG-BA cells can be abrogated by the SP1 inhibitor mithramycin A (Figure 6D).

Interestingly, the effect of cell density on endosialin gene expression could be observed both under normoxic and hypoxic conditions. In hypoxia, cell density further augmented the hypoxic induction, indicating that these regulatory mechanisms may be integrated in modulation of endosialin expression (Figure 6E).

\section{DISCUSSION}

Several studies have reported selective upregulation of endosialin in the vasculature and activated fibroblasts of various human tumours, and a link between endosialin expression and induced angiogenesis has been proposed. However, the molecular mechanisms that control endosialin expression have remained elusive (Rettig et al, 1992; Brady et al, 2004; Davies et al, 2004; Madden et al, 2004; Dolznig et al, 2005; MacFadyen et al, 2005; Huber et al, 2006).

In this study, we demonstrate for the first time that hypoxia, which is a driving force of angiogenesis under both physiological and pathological conditions, regulates endosialin gene transcription and that the hypoxic induction is mediated predominantly by the HIF-2 transcription factor. Our finding is compatible with the expression pattern and target gene preference of the HIF- $2 \alpha$ subunit. In contrast to the structurally and functionally related HIF- $1 \alpha$ subunit that is ubiquitously expressed, HIF- $2 \alpha$ is confined to tissues and cell types, which also express endosialin, including blood vessels, fibroblasts and glial cells (Wiesener et al, 2003). In addition, HIF- $2 \alpha$ (rather than HIF- $1 \alpha$ ) regulates a subset of genes involved in angiogenic responses, such as Tie-2/TEK, VEGFR1 (Flt-1), VEGFR2 (Kdr/Flk-1), VE-cadherin, EPO and TGF- $\alpha$ (Tian et al, 1997; Takeda et al, 2004; Elvert et al, 2003; Raval et al, 2005; Le Bras et al, 2007). Moreover, the kinetics of endosialin induction by hypoxia with a maximum level achieved during a $24 \mathrm{~h}$ incubation period as well as an optimal oxygen concentration between 2 and $5 \%$ (data not shown) better correspond to the temporal profile and activation optimum of HIF- $2 \alpha$, which increases with time at moderate-to-mild hypoxia, whereas HIF- $1 \alpha$ stabilisation occurs at lower oxygen concentration and its levels are reduced at prolonged hypoxia (Löfstedt et al, 2007). Thus, the endosialin 

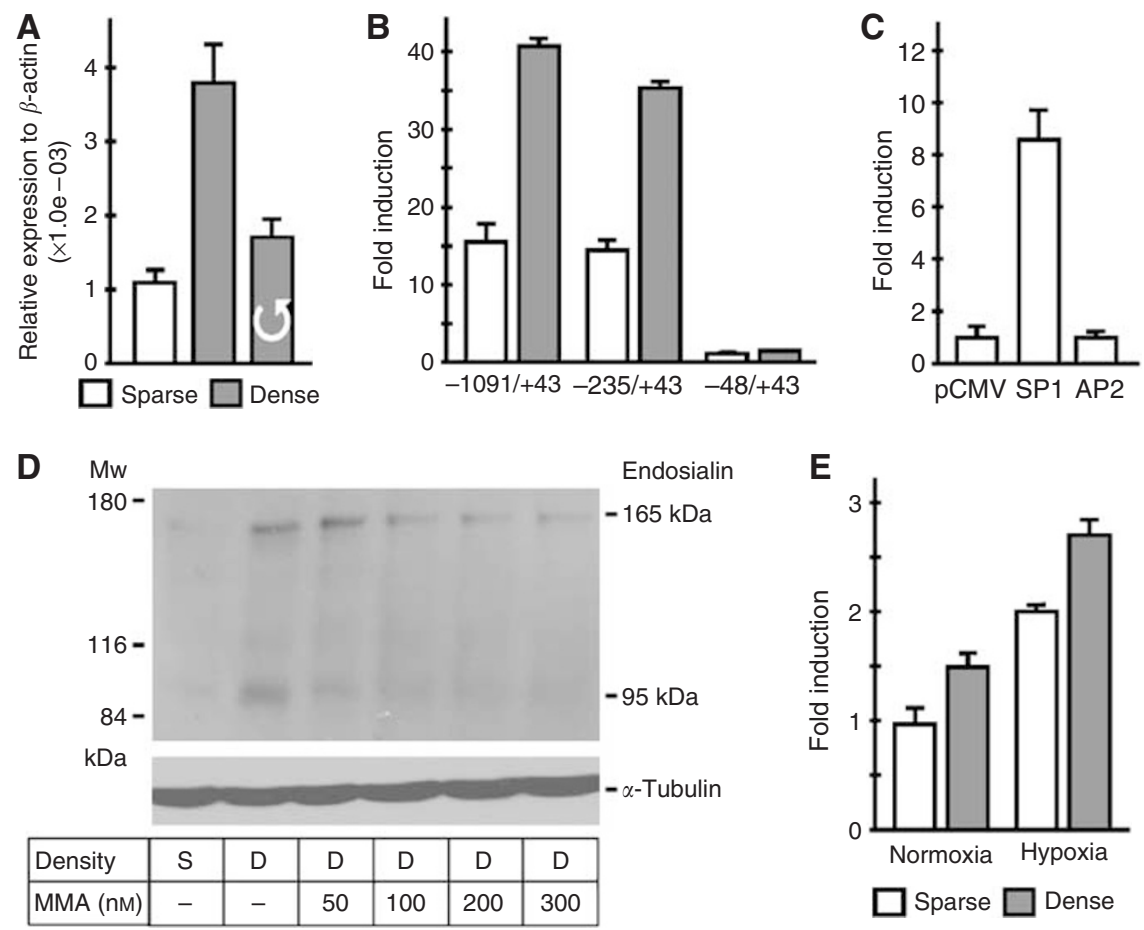

Figure 6 Expression of endosialin in response to high cell density. (A) 42-MG-BA cells were plated to form sparse $\left(S, 12000 \mathrm{cells}^{-2} \mathrm{~cm}^{-2}\right.$ and dense $(\mathrm{D}$, 48000 cells $\mathrm{cm}^{-2}$ ) monolayers and incubated for $24 \mathrm{~h}$ in normoxia. Gentle stirring was applied to dense cells to eliminate pericellular hypoxia. Total RNA was extracted and expression of endosialin mRNA was analysed by quantitative RT-PCR and normalised to $\beta$-actin levels. Stirring reduced the densityelevated expression of endosialin. (B) Endosialin promoter activity in sparse vs dense HeLa cells was assessed by transfection of $-109 \mid /+43,-235 /+43$ and $-48 /+43$ fragments in PGL3-basic vector $(1 \mu \mathrm{g})$ with pRL-TK plasmid $(50 \mathrm{ng})$ as described in Figure 2 . Effect of density was not observed in the shortest promoter construct. (C) Sparse HeLa cells were co-transfected with -235/ + 43 promoter fragment in pGL3-basic (I $\mu$ g), pRL-TK plasmid (50 ng) and SPI or AP-2 expression vectors (I $\mu$ g each). Empty PCMV plasmid was used to adjust total DNA content in the control sample. The promoter activity was assessed after $24 \mathrm{~h}$ incubation in normoxia as described in Figure 2. SPI but not AP-2 induced endosialin promoter activity. (D) Immunoblotting analysis of endosialin expression in sparse (S) and dense (D) 42-MG-BA cells treated with increasing concentrations of the SPI inhibitor mithramycin A (MMA). M78 MAb revealed increased expression of endosialin in the dense cells and progressively reduced levels in MMA-treated cells. $\alpha$-Tubulin antibody was used for a loading control. (E) Additive effect of high cell density and hypoxia on endosialin promoter activity was evaluated in HeLa cells transfected with the $-1091 /+43$ promoter fragment as described in Figure 2A.

appears to be a new angiogenesis-related target of the HIF-2 transcription factor.

In further support of this model, the Ets-1 transcription factor contributes to activation of endosialin expression. Physical and functional interaction between HIF-2 and ETS family members appears to be required for the proper hypoxic regulation of several HIF-2-target genes (Aprelikova et al, 2006). Here, we demonstrate that HIF-2 cooperating with Ets-1 can transactivate the endosialin promoter through two distinct regions: a distal region, possibly serving as an enhancer and a proximal region representing the core promoter. The distal region contains a module composed of the functional HRE site and the adjacent Ets-1-binding site. In such a constellation, HIF-2 can directly bind DNA and at the same time interact with Ets-1 through the $\mathrm{N}$-terminal transactivation domain, as has been shown for the other HIF-2-target genes including VEGFR2 (Elvert et al, 2003). The proximal region of the endosialin promoter is hypoxia-responsive despite the absence of any apparent HRE. On this part of the promoter, HIF-2 seems to operate through the interaction with Ets-1 and its two cognate EBS elements. The paradigm for this mode of HIF-2 action can be found in VE-cadherin promoter (Le Bras et al, 2007).

The proximal promoter region mediates also a cell densitydependent activation response. This effect is partly related to pericellular hypoxia and as such might again involve HIF-2, the stabilisation and activation of which requires just a mild lowering of oxygen tension (Löfstedt et al, 2007). As the SP1 transcription

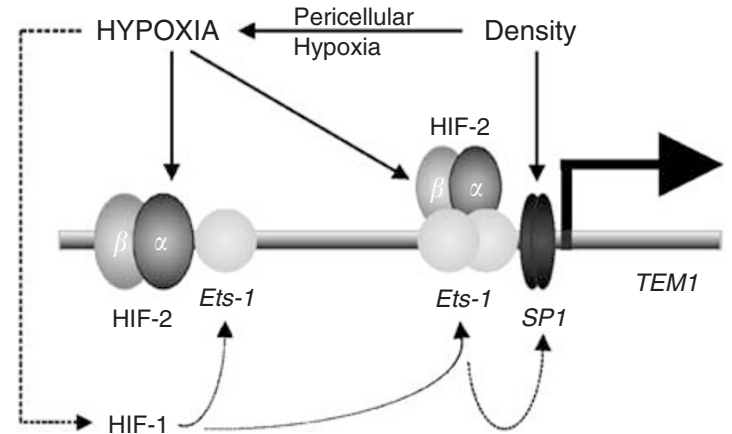

Figure 7 Schematic illustration of the molecular anatomy of the endosialin promoter and regulatory pathways induced by hypoxia and cell density. Distal part of the promoter contains adjacent hypoxia-responsive element (HRE) and ETS transcription factor-binding site (EBS) element and transmits hypoxic signalling through hypoxia-inducible factor (HIF)-2 directly binding to DNA and cooperating with Ets-I. Proximal part of the promoter contains two EBS elements (but not HRE) and hypoxia signalling is mediated by HIF-2 through Ets-I and two EBS elements. High cell density contributes to endosialin activation by means of SPI-binding sites in the proximal promoter and partially feeds the hypoxic pathway by pericellular hypoxia. Moreover, hypoxia might influence activation of endosialin indirectly through HIF-I that upregulates expression of Ets-I, which in turn upregulates expression of SPI. On the basis of this model, hypoxia and density cross-talk to induce endosialin transcription. 
factor is capable to cause a considerable induction of endosialin in sparse monolayer cell culture, and inhibition of SP1 reduces induction of endosialin expression by high cell density, SP1 seems to be a critical factor mediating this regulatory effect.

Thus, as schematically summarised in Figure 7, the transcription factors HIF-2 and Ets-1 mediate hypoxic responses, whereas SP1 functions as a mediator of density effects. Importantly, there is a cross-talk between these regulatory pathways. However, the situation might be more complex, as SP1 was found to be a transcriptional target of Ets-1 (Sato and Furukawa, 2007), and Ets-1 expression is enhanced by HIF-1 (Oikawa et al, 2001). In the case of endosialin expression, we observed that the gene is regulated by hypoxia under conditions that stabilise and activate HIF-2 and/or HIF-1. It is conceivable that HIF-1 does not need to be directly bound to endosialin promoter to mediate this effect, but induces Ets-1 expression and thus supports formation of the cooperative complex between Ets-1 and HIF-2. Elevated expression of Ets-1 then presumably leads to increased transcription of SP1, which can further stimulate activity of endosialin promoter.

The involvement of hypoxia in regulation of endosialin gene expression sheds new light on its possible biological significance in vascular remodelling. According to recent data, endosialin is preferentially associated with pericytes and stromal fibroblasts, but not with endothelial cells, as suggested in earlier studies (MacFadyen et al, 2005; Christian et al, 2008; Simonavicius et al, 2008). Pericytes form an outer sheath around the endothelium and play an important role in maturation of blood microvessels and stabilisation of vascular network, whereas stromal fibroblasts stimulate angiogenesis by trophic effects and extracellular matrix reorganisation (Jain, 2003; Armulik et al, 2005). In contrast to normal tissues, tumours are characterised by continuously ongoing angiogenesis with high proliferation rate of endothelial cells and diminished maturation of blood vessels (Bergers and Benjamin, 2003). The functionally defective vasculature gives rise to hypoxia in the tumour tissue, resulting in excessive production of proangiogenic factors and a new round of angiogenesis accompanied by tumour expansion. To allow for a new blood vessel formation, the pericytes of pre-existing vessels have to be detached from endothelial cells and enable them to respond to mitogenic signals. It is possible that hypoxia (and also dense intercellular contacts) upregulate expression of endosialin to relieve pericyte-endothelial interactions and/or to modulate local tumour stroma, and thereby facilitate migration of dividing endothelial cells and sprouting of new blood vessels. Indeed, endosialin was found to support an invasive tumour phenotype in the mouse knock-out model and modulate in vitro migration, which are phenomena well known to be linked to hypoxia and angiogenesis (Nanda et al, 2006; Tomkowicz et al, 2007). This hypothesis could also explain why endosialin expression is detectable in the developing embryo, where new blood vessels form to feed extensive hypoxic areas, but not in adult tissues, where hypoxia is generally absent, and vascular network is usually mature and quiescent.

Although further functional studies are clearly required to prove the above-proposed role for endosialin, this study clarifies important aspects of its regulation and provides a rational frame for future investigations towards a better understanding of its biological significance.

\section{ACKNOWLEDGEMENTS}

This study was supported by the grants from the Slovak Scientific Grant Agency (VEGA 2/6112) and from EC (EUROXY project LSHC-CT-2003-502932).

Supplementary Information accompanies the paper on British Journal of Cancer website (http://www.nature.com/bjc)

\section{REFERENCES}

Aprelikova O, Wood M, Tackett S, Chandramouli GV, Barrett JC (2006) Role of ETS transcription factors in the hypoxia-inducible factor-2 target gene selection. Cancer Res 66: $5641-5647$

Armulik A, Abramsson A, Betsholtz C (2005) Endothelial/pericyte interactions. Circ Res 97: 512-523

Bergers G, Benjamin LE (2003) Tumorigenesis and angiogenic switch. Nat Rev Cancer 3: 401-410

Brady J, Neal J, Sadakar N, Gasque P (2004) Human endosialin (tumor endothelial marker 1) is abundantly expressed in highly malignant and invasive brain tumors. J Neuropathol Exp Neurol 63: $1274-1283$

Carson-Walter EB, Watkins DN, Nanda A, Vogelstein B, Kinzler KW, St Croix B (2001) Cell surface tumor endothelial markers are conserved in mice and humans. Cancer Res 61: 6649-6655

Christian S, Ahorn H, Koehler A, Eisenhaber F, Rodi HP, Garin-Chesa P, Park JE, Rettig WJ, Lenter MC (2001) Molecular cloning and characterization of endosialin, a C-type lectin-like cell surface receptor of tumor endothelium. J Biol Chem 276: 7408-7414

Christian S, Winkler R, Helfrich I, Boos AM, Besemfelder E, Schadendorf D, Augustin HG (2008) Endosialin (Tem1) is a marker of tumor-associated myofibroblasts and tumor vessel-associated mural cells. Am J Pathol 172: $486-494$

Davies G, Cunnick GH, Mansel RE, Mason MD, Jiang WG (2004) Levels of expression of endothelial markers specific to tumour-associated endothelial cells and their correlation with prognosis in patients with breast cancer. Clin Exp Metastasis 21: 31-37

Dolznig H, Schweifer N, Puri C, Kraut N, Rettig WJ, Kerjaschki D, Garin-Chesa P (2005) Characterization of cancer stroma markers: in silico analysis of an mRNA expression database for fibroblast activation protein and endosialin. Cancer Immun 5: 10
Elvert G, Kappel A, Heidenreich R, Englmeier U, Lanz S, Acker T, Rauter M, Plate K, Sieweke M, Breier G, Flamme I (2003) Cooperative interaction of hypoxia-inducible factor-2alpha (HIF-2alpha) and Ets-1 in the transcriptional activation of vascular endothelial growth factor receptor-2 (Flk-1). J Biol Chem 278: 7520 - 7530

Fukumura D, Jain RK (2007) Tumor microvasculature and microenvironment: targets for anti-angiogenesis and normalization. Microvasc Res 74: $72-84$

Harris AL (2002) Hypoxia - a key regulatory factor in tumour growth. Nat Rev Cancer 2: $38-47$

Hickey MM, Simon MC (2006) Regulation of angiogenesis by hypoxia and hypoxia-inducible factors. Curr Top Dev Biol 76: 217-257

Huber MA, Kraut N, Schweifer N, Dolznig H, Peter RU, Schubert RD, Scharffetter-Kochanek K, Pehamberger H, Garin-Chesa P (2006) Expression of stromal cell markers in distinct compartments of human skin cancers. J Cutan Pathol 33: 145-155

Jain RK (2003) Molecular regulation of vessel maturation. Nat Med 9: 685-693 Le Bras A, Lionneton F, Mattot V, Lelièvre E, Caetano B, Spruyt N, Soncin F (2007) HIF-2alpha specifically activates the VE-cadherin promoter independently of hypoxia and in synergy with Ets-1 through two essential ETS-binding sites. Oncogene 26: 7480 - 7489

Legraverend C, Hannah RR, Eisen HJ, Owens IS, Nebert DW, Hankinson O (1982) Regulatory gene product of the Ah locus. Characterization of receptor mutants among mouse hepatoma clones. J Biol Chem 257: 6402-6407

Liao D, Johnson RS (2007) Hypoxia: a key regulator of angiogenesis in cancer. Cancer Metastasis Rev 26: $281-290$

Loots GG, Ovcharenko I (2004) rVista 2.0: evolutionary analysis of transcription factor binding sites. Nucleic Acids Res 32(Web Server Issue): W217- W221 
Löfstedt T, Fredlund E, Holmquist-Mengelbier L, Pietras A, Ovenberger M, Poellinger L, Påhlman S (2007) Hypoxia inducible factor-2alpha in cancer. Cell Cycle 6: 919-926

Löfstedt T, Jögi A, Sigvardsson M, Gradin K, Poellinger L, Påhlman S, Axelson $\mathrm{H}$ (2004) Induction of ID2 expression by hypoxia-inducible factor-1: a role in dedifferentiation of hypoxic neuroblastoma cells. J Biol Chem 279: $39223-39231$

MacFadyen JR, Haworth O, Roberston D, Hardie D, Webster MT, Morris HR, Panico M, Sutton-Smith M, Dell A, van der Geer P, Wienke D, Buckley CD, Isacke CM (2005) Endosialin (TEM1, CD248) is a marker of stromal fibroblasts and is not selectively expressed on tumour endothelium. FEBS Lett 579: 2569-2575

MacFadyen J, Savage K, Wienke D, Isacke CM (2007) Endosialin is expressed on stromal fibroblasts and CNS pericytes in mouse embryos and is downregulated during development. Gene Expr Patterns 7: 363-369

Madden SL, Cook BP, Nacht M, Weber WD, Callahan MR, Jiang Y, Dufault MR, Zhang X, Zhang W, Walter-Yohrling J, Rouleau C, Akmaev VR, Wang CJ, Cao X, St Martin TB, Roberts BL, Teicher BA, Klinger KW, Stan RV, Lucey B, Carson-Walter EB, Laterra J, Walter KA (2004) Vascular gene expression in nonneoplastic and malignant brain. Am J Pathol 165: 601-608

Mason GG, Witte AM, Whitelaw ML, Antonsson C, McGuire J, Wilhelmsson A, Poellinger L, Gustafsson JA (1994) Purification of the DNA binding form of dioxin receptor. Role of the Arnt cofactor in regulation of dioxin receptor function. J Biol Chem 269: 4438-4449

Nanda A, Karim B, Peng Z, Liu G, Qiu W, Gan C, Vogelstein B, St Croix B, Kinzler KW, Huso DL (2006) Tumor endothelial marker 1 (Tem1) functions in the growth and progression of abdominal tumors. Proc Natl Acad Sci USA 103: 3351 - 3356

Oikawa M, Abe M, Kurosawa H, Hida W, Shirato K, Sato Y (2001) Hypoxia induces transcription factor ETS-1 via the activity of hypoxia-inducible factor-1. Biochem Biophys Res Commun 289: 39-43

Opavsky R, Haviernik P, Jurkovicova D, Garin MT, Copeland NG, Gilbert DJ, Jenkins NA, Bies J, Garfield S, Pastorekova S, Oue A, Wolff L (2001) Molecular characterization of the mouse Tem1/endosialin gene regulated by cell density in vitro and expressed in normal tissues in vivo. J Biol Chem 276: $38795-38807$

Perzelová A, Máciková I, Mráz P, Bízik I, Steno J (1998) Characterization of two new permanent glioma cell lines 8-MG-BA and 42-MG-BA. Neoplasma 45: 25-29

Quandt K, Frech K, Karas H, Wingender E, Werner T (1995) MatInd and MatInspector: new fast and versatile tools for detection of consensus matches in nucleotide sequence data. Nucleic Acids Res 23: 4878-4884

Raval RR, Lau KW, Tran MG, Sowter HM, Mandriota SJ, Li JL, Pugh CW, Maxwell PH, Harris AL, Ratcliffe PJ (2005) Contrasting properties of hypoxia-inducible factor 1 (HIF-1) and HIF-2 in von Hippel-Lindauassociated renal cell carcinoma. Mol Cell Biol 25: 5675-5686

Rettig WJ, Garin-Chesa P, Healey JH, Su SL, Jaffe EA, Old LJ (1992) Identification of endosialin, a cell surface glycoprotein of vascular endothelial cells in human cancer. Proc Natl Acad Sci USA 89: $10832-10836$

Ruas JL, Lendahl U, Poellinger L (2007) Modulation of vascular gene expression by hypoxia. Curr Opin Lipidol 18: 508-514

Ruas JL, Poellinger L (2005) Hypoxia-dependent activation of HIF into a transcriptional regulator. Semin Cell Dev Biol 16: 514-522

Rupp C, Dolznig H, Puri C, Sommergruber W, Kerjaschki D, Rettig WJ, Garin-Chesa P (2006) Mouse endosialin, a C-type lectin-like cell surface receptor: expression during embryonic development and induction in experimental cancer neoangiogenesis. Cancer Immun 6: 10

Sato T, Furukawa K (2007) Sequential action of Ets-1 and Sp1 in the activation of the human beta-1,4-galactosyltransferase $\mathrm{V}$ gene involved in abnormal glycosylation characteristic of cancer cells. J Biol Chem 282: $27702-27712$

Sheta EA, Trout H, Gildea JJ, Harding MA, Theodorescu D (2001) Cell density mediated pericellular hypoxia leads to induction of HIF-1alpha via nitric oxide and Ras/MAP kinase mediated signaling pathways. Oncogene 20: 7624-7634

Simonavicius N, Robertson D, Bax DA, Jones C, Huijbers IJ, Isacke CM (2008) Endosialin (CD248) is a marker of tumor-associated pericytes in high-grade glioma. Mod Pathol 21: 308-315

St Croix B, Rago C, Velculescu V, Traverso G, Romans KE, Montgomery E, Lal A, Riggins GJ, Lengauer C, Vogelstein B, Kinzler KW (2000) Genes expressed in human tumor endothelium. Science 289: 1197-1202

Takeda N, Maemura K, Imai Y, Harada T, Kawanami D, Nojiri T, Manabe I, Nagai R (2004) Endothelial PAS domain protein 1 gene promotes angiogenesis through the transactivation of both vascular endothelial growth factor and its receptor, Flt-1. Circ Res 95: 146-153

Teicher BA (2007) Newer vascular targets: endosialin (Review). J Int Oncol 30: $305-312$

Tian H, McKnight SL, Russell DW (1997) Endothelial PAS domain protein 1 (EPAS1), a transcription factor selectively expressed in endothelial cells. Genes Dev 11: $72-82$

Tomkowicz B, Rybinski K, Foley B, Ebel W, Kline B, Routhier E, Sass P, Nicolaides NC, Grasso L, Zhou Y (2007) Interaction of endosialin/TEM1 with extracellular matrix proteins mediates cell adhesion and migration. Proc Natl Acad Sci USA 104: 17965-17970

Virgintino D, Girolamo F, Errede M, Capobianco C, Robertson D, Stallcup WB, Perris R, Roncali L (2007) An intimate interplay between precocious, migrating pericytes and endothelial cells governs human fetal brain angiogenesis. Angiogenesis 10: $35-45$

Whitelaw M, Pongratz I, Wilhelmsson A, Gustafsson JA, Poellinger L (1993) Ligand-dependent recruitment of the Arnt coregulator determines DNA recognition by the dioxin receptor. Mol Cell Biol 13: 2504-2514

Wiesener MS, Jürgensen JS, Rosenberger C, Scholze CK, Hörstrup JH, Warnecke C, Mandriota S, Bechmann I, Frei UA, Pugh CW, Ratcliffe PJ, Bachmann S, Maxwell PH, Eckardt KU (2003) Widespread hypoxiainducible expression of HIF-2alpha in distinct cell populations of different organs. FASEB J 17: $271-273$ 